\title{
SINESTESIA, ARTE E DEFICIÊNCIA VISUAL Aplicação de um método didático-pedagógico para apreciação de pinturas por alunos não visuais na Educação Básica
}

\section{SYNESTHESIA, ART AND VISUAL IMPAIRMENT Application of a didatic-pedagogical method for appreciation of paintings by non-visual students in Basic Education}

\author{
DOI: http://dx.doi.org/10.5965/1984317815032019008 \\ Luís Müller Posca \\ Universidade Federal de Roraima \\ luis.mp@msn.com \\ João Henrique Lodi Agreli \\ Universidade Federal de Uberlândia \\ agreli@hotmail.com
}

\section{RESUMO}

Este estudo propõe demonstrar como o ensino das Artes Visuais pode ser adaptado ao aluno deficiente visual da Educação Básica. Considerando-se o princípio de que a Arte está ligada aos sentimentos humanos, muitos acreditam que, por não enxergar, esse aluno está excluído daquilo que se refere à poética visual. Diante das dificuldades encontradas no processo de inclusão de alunos deficientes visuais no ensino de Artes Visuais e da ausência de materiais de apoio ao docente adaptados a esse público, defendemos que, por intermédio do uso de pranchas táteis, trabalhadas levandose em consideração a sinestesia (fenômeno que provoca reações multissensoriais, misturando mais de um sentido diante de um objeto de análise), é possível que o aluno não visual possa apreciar pinturas nas aulas de arte. Aqui, apresentamos um relato de experiência sobre a criação e a aplicação de um método didático-pedagógico de ensino-aprendizagem de Artes Visuais unindo essas pranchas táteis a uma atmosfera sinestésica para alunos não visuais da Educação Básica, com a finalidade de pensar uma aula de Arte significativa e inclusiva aos alunos deficientes visuais

Palavras-chave: Artes visuais. Deficientes visuais. Sinestesia. Método didáticopedagógico, Pranchas táteis.

\begin{abstract}
This study proposes to demonstrate how the teaching of the Visual Arts can be adapted to the visual impairment student of Basic Education. Considering the basis that Art is linked to human feelings, many people believe that a student who cannot see is excluded from what refers to visual poetics. In view of the difficulties find in the process of inclusion of visually impaired students in the teaching of visual arts and the absence of teaching materials adapted to this public, we argue that, through the use of tactile planks, which are worked out with regard to synesthesia (a phenomenon that provokes multisensory reactions, mixing more than one sense before an object of analysis), it is possible that the non-visual student can appreciate paintings in art classes. Here, we present an experience report on the creation and application of a didactic-pedagogical method of teaching-learning of Visual Arts joining these tactile planks to a synaesthetic atmosphere for non-visual students of Basic Education, with the purpose of thinking a meaningful and inclusive Art class to the visually impaired students.
\end{abstract}

Keywords: Visual arts. Visually impaired. Synesthesia. Didactic-pedagogical method, Tactile planks. 


\section{INTRODUÇÃO}

Durante os anos de docência na disciplina Arte (2008 - 2016), convivi com diversas realidades escolares em escolas públicas no interior do Estado de São Paulo. Nesses anos, como professor na Educação Básica, lecionei para uma grande quantidade de alunos que apresentam necessidades educacionais especiais, os alunos da famosa "inclusão escolar". A proposta da inclusão é regulamentada pela Lei de Diretrizes e Bases da Educação Nacional (Lei n. 9.394/96), no seu art. 58, cap. V, que institui a Educação Especial como "modalidade escolar para educandos portadores de necessidades especiais, preferencialmente na rede regular de ensino" (BRASIL, 1996).

Diante dessa legislação, avanços foram feitos, como por exemplo o surgimento da Lei Brasileira de Inclusão da Pessoa com Deficiência - Estatuto da Pessoa com Deficiência, Lei $n^{\circ}$ 13.146, de 6 de julho de 2015 (BRASIL, 2015). Porém, falhas ainda persistem nesse processo da educação inclusiva, especialmente sobre as possibilidades abertas sobre como desenvolver as adaptações curriculares citadas nas legislações de ensino e como isso tem sido desenvolvido nas redes de ensino públicas do País.

Será que os avanços feitos com a regulamentação da inclusão escolar foram de fato significativos? Ou garantir a inclusão dos discentes apenas para estatísticas é o que vem acontecendo? Trago essa discussão a princípio, a fim de que possamos pensar no ensino de Arte para alunos deficientes visuais. Incluir o discente não visual em uma aula de Artes Visuais, sem maiores recursos que possam, de fato, fazê-lo compreender e fruir sobre as obras de arte apresentadas em sala de aula não seria reproduzir uma exclusão social? Qual função a aula de Arte vai exercer na educação desse aluno?

Portanto, neste artigo, abordamos o recorte do ensino de Artes Visuais aos alunos não visuais de escolas públicas na Educação Básica, mais especificamente, o tema: apreciação e fruição de pinturas por esse público dentro das aulas de Arte. 
Nesse sentido, este estudo apresenta aspectos norteadores para a possibilidade de criação de um material adaptado e de um método didáticopedagógico que propicie uma experiência artística dentro do ambiente escolar para alunos não visuais.

Apresentamos primeiramente, o conceito de sinestesia, com um enfoque para a possibilidade de esse fenômeno ressignificar a ausência da visão na contemplação da arte por intermédio de outros canais sensoriais. $\mathrm{Na}$ sequência, trataremos da criação do material didático adaptado à fruição de obras de arte para esse público, suas possíveis aplicações em contextos da Educação Básica e a validação desse material, juntamente com um método didático-pedagógico de ensino e aprendizagem, por alunos deficientes visuais participantes, desse nível de ensino. Finalmente, serão apresentadas a conclusão deste artigo e as referências utilizadas.

\section{SINESTESIA E ARTE}

Para fundamentarmo-nos acerca da ideia de um ensino voltado para a "multissensorialidade", é importante que discorramos sobre o fenômeno da sinestesia aplicado às Artes Visuais, uma vez que consideramos esse fenômeno como principal mediador para a fruição estética de obras de arte para as pessoas não visuais.

A palavra "sinestesia" deriva do grego, syn, que significa "união", e de aisthesis, que significa "sensação". Logo, é a "união de sensações". De acordo com o dicionário eletrônico Houaiss (HOUAISS; VILLAR, 2009, n.p.), "sinestesia" pode ser definida da seguinte maneira:

Associação de palavras ou expressões que combinam várias e diferentes sensações humanas, numa só representação; mistura de sensações, dos sentidos (visão, audição, tato, paladar, olfato): dia com gosto de chuva fria.

[Psicologia] Associação espontânea de essência psicológica que se define pela mistura de duas sensações ou de duas imagens distintas: cheiro de verde. 
Neste artigo, interessou-nos a estreita relação desse fenômeno com aquilo que estamos nos propondo a analisar, ou seja, a apreciação de obras de arte na ausência da visão.

Para iniciarmos uma reflexão sobre os sentidos relacionados à Arte, iniciamos este tópico com um pensamento de Viktor Chklovski acerca da essência da Arte: "E eis que para devolver a sensação de vida, para sentir os objetos, para provar que pedra é pedra, existe o que se chama arte. O objetivo da arte é dar a sensação do objeto como visão e não como reconhecimento" (CHKLOVSKI, 1978, p. 45).

Nessa fala de Chklovski (1978), podemos fazer uma relação entre Arte e Vida: em sua escrita, fica evidente o caráter vital da Arte para as pessoas; traz à tona o fato de que o objetivo maior da Arte é dar a sensação do objeto como visão. E, quando o autor apresenta a visão, podemos nos questionar sobre a ausência dela e pensarmos nas sensações e como a captação do objeto artístico pode acontecer por meio destas. Será que a visão é tão importante assim para que a arte seja arte?

A literatura vai nos mostrar que nem sempre é assim. De acordo com Heyrman ${ }^{1}$ (2005 apud PRESA, 2008), como as obras de arte são carregadas de significados, a sinestesia se apresenta como a melhor maneira para que se faça uma interpretação e fruição artísticas. Vejamos algumas relações apresentadas pelo autor entre Arte e sinestesia:

A arte e a sinestesia são ambas resultantes da união de sensações;

A arte oferece formas multissensoriais de comunicar;

Uma aproximação sinestésica à realidade é uma das fontes primárias da arte;

A sinestesia aparece em todas as formas de arte (HEYRMAN, 2005 apud PRESA, 2008, p. 56).

\footnotetext{
1 HEYRMAN, Hugo. 1. First International Conference on Art and Synesthesia, Espanha. Art and Synesthesia: in search of the synesthetic experience. Espanha: Universidad de Almería, 2005. n.p. Disponível em: <http://www.doctorhugo.org/synaesthesia/art/index.html>. Acesso em: 19 abr. 2016.
} 
Deve-se levar em conta que o fenômeno sinestésico acontece em primeira pessoa, algo como uma voz de sua consciência, invisível para as outras pessoas e imperceptível até que esse sujeito externalize seus pensamentos e percepções. "Através da arte, a experiência sinestésica pode ser visível aos outros. Ela torna-se comunicável e mistura-se ainda com uma visão pessoal de cada um que a compartilha" (HEYRMAN, 2005 apud PRESA, 2008, p. 56). Logo, as obras de arte podem fazer emergir sensações sinestésicas e, com isso, traz-se à tona, também, a intenção do artista, pois veremos que alguns artistas podem provocar em suas obras sensações sensoriais de forma intencional.

Em seu livro Do espiritual na arte, o artista Wassily Kandinsky cita várias metáforas sinestésicas que vão além da associação de formas, cores e sons, típicas das análises de suas pinturas. Descreve sensações sinestésicas como meios de se atingir o espiritual e a alma. Na abertura do capítulo sobre pintura, em a "Ação da cor", Kandinsky (2000, p. 65) faz uso da sinestesia para descrever a sensação do espectador diante da apreciação de uma cor como degustação de uma fina iguaria.

Do ponto de vista estritamente físico, o olho sente a cor. Experimenta suas propriedades, é fascinado por sua beleza. A alegria penetra na alma do espectador, que a saboreia como um gourmet, uma iguaria. O olho recebe uma excitação semelhante à ação que tem sobre o paladar uma comida picante. Mas também pode ser acalmado ou refrescado como um dedo quando toca uma pedra de gelo.

Apesar de Kandinsky (2000) ser considerado como um possuidor da "sinestesia desenvolvimental2", nos estudos de Presa (2008, p. 62) verificamos que esse artista deve ser considerado, na verdade, como um "pseudosinestesista", uma vez que a sinestesia verificada em suas obras foi aprendida por treino ou pelo hábito e uso cultural. Podemos inferir que a sua

\footnotetext{
2 Aquela que acompanha o sujeito desde o início de sua vida, sem que outro fenômeno a tenha desencadeado, diferente da sinestesia "adquirida" que tem o seu início devido ao uso de substâncias alucinógenas (PRESA, 2008, p.62).
} 
intenção artística sempre esteve ligada a incutir em suas obras uma relação multissensorial por intermédio da cor para que conseguisse, assim, alcançar a alma do espectador.

Kandinsky teve como objectivo superior criar a chamada "gesamtkunstwerk ${ }^{3 "}$ (trabalho artístico total). A sua lógica para essa criação era simples: quantos mais sentidos fossem despertados ao olhar para a sua obra, maior probabilidade existia em chegar à espiritualidade mais profunda de cada um (PRESA, 2008, p. 64).

Contudo, verificamos que Kandinsky (2000), em suas obras, não pretendia demonstrar ser um possuidor da sinestesia. Mas suas intenções artísticas objetivavam que seus espectadores experimentassem sensações que evocassem essa dimensão sinestésica ao apreciar seus trabalhos, aproximando-o de uma experiência espiritual por intermédio das sensações vivenciadas com as obras. Além desse exemplo, historicamente verifica-se que diversas obras de arte são carregadas de sinestesias e que a relação entre a intenção artística e a experiência do espectador é que vão criar uma real significação dessas sensações.

É comum ouvirmos que a pessoa com uma deficiência supre a ausência de um sentido aguçando seus outros sentidos. $E$ isso faz muito sentido quando tratamos da pessoa com deficiência visual. Na ausência da visão, tato, audição e olfato são colocados em maior evidência. Mas isso não acontece apenas em situações concretas do cotidiano: toda a questão afetiva/emotiva do deficiente visual é construída também com base nesses sentidos. Sobre essas vivências passadas, ressaltando a questão afetiva das lembranças, alguns autores endossam que as percepções diferem qualitativamente das características físicas do estímulo, porque o cérebro dele extrai uma informação e a interpreta em função de experiências anteriores com as quais ela se associe. Estudos de

\footnotetext{
3 Em português, Obra de arte total, que é um conceito estético oriundo do romantismo alemão do século XIX. Geralmente associado ao compositor alemão Richard Wagner, o termo refere-se à conjugação de música, teatro, canto, dança e artes plásticas, em uma única obra de arte (PRESA, 2008, p.64).
} 
Sacks $^{4}$ (2007), Cytowic ${ }^{5}$ (1995) e Reily6 (2008) ainda mostram que as crianças cegas tendem a se aproximar do universo da música com muito mais facilidade do que as crianças videntes, inclusive, em muitos casos, possuindo o ouvido absoluto7 com facilidade dez vezes maior do que videntes na mesma situação (apud MARQUES, 2016).

Essa estreita relação entre a sinestesia e a cegueira, como atestadas no exemplo acima, corroboram com a ideia de que diante da ausência da visão os demais sentidos se tornam aguçados.

\begin{abstract}
Mas a única causa significativa de sinestesia adquirida permanente é a cegueira. A perda da visão, especialmente no começo da vida, pode, paradoxalmente, levar a imagens mentais visuais intensificadas e a todo tipo de conexões intersensoriais e sinestesias. A rapidez com que a sinestesia pode surgir em seguida à cegueira dificilmente permitiria a formação de novas conexões anatômicas no cérebro. Isso sugere que, em vez de novas conexões, o que ocorre é um fenômeno de liberação: a remoção de uma inibição normalmente imposta pelo sistema visual quando este funciona plenamente. Desse modo, a sinestesia decorrente da cegueira seria análoga às alucinações visuais (síndrome de Charles Bonnet ${ }^{8}$ ), freqüentemente associadas ao aumento de deficiência visual, ou às alucinações musicais às vezes associadas à surdez progressiva (SACKS, 2007 apud MARQUES, 2016, p. 45).
\end{abstract}

\footnotetext{
4 SACKS, Oliver. Alucinações musicais. São Paulo: Companhia das Letras, 2007.

5 CYTOWIC, Richard E. Synesthesia: phenomenology and neuropsychology - a review of current knowledge. Psyche: an Interdisciplinary Journal of Research on Consciousness, v.2, n. 10, 1995.
}

6 REILY, Lucia. Músicos Cegos ou cegos músicos: representações de compensação sensorial na História da Arte. Cadernos Cedes, Campinas, v. 28, n. 75, 2008. Disponível em: http:// www.cedes.unicamp.br. Acesso em: 16 fev. 2016.

7 É a capacidade que uma pessoa tem de formar uma imagem auditiva interna de qualquer tom musical marcado por um símbolo apropriado (nota, letra), de modo que se possa naturalmente identificar qualquer tom acusticamente apresentado (ouvido absoluto passivo) e, mais raramente, cantar qualquer tom de memória, sem referências externas (ouvido absoluto ativo) (CONHECIMENTO GERAL, 2016).

8 A síndrome de Charles Bonnet é uma doença que faz com que pacientes com pouca visão tenham alucinações visuais. Essa doença foi descrita por Charles Bonnet em 1769. Essas visões podem durar minutos ou até horas. Geralmente são nítidas, coloridas, silenciosas e complexas, desaparecendo abruptamente, e foi introduzida na Psiquiatria de língua Inglesa em 1982 (ARAGUAIA, 2017). 
Uma vez apresentada à base teórica acerca da sinestesia e da relação desta com a cegueira, trabalhamos com a possibilidade de apreciação do mundo por meio das sensações advindas de outros canais sensoriais para pessoas não visuais. Essa "sinestesia adquirida" por pessoas cegas, descrita por Sacks (2007 apud MARQUES, 2016), é exatamente a ideia na qual nos apoiamos nesta pesquisa.

Para que uma pessoa possa estimular o aprendizado por intermédio de um estímulo tátil, o bom desenvolvimento biológico e afetivo desse sentido precisa ser permanente e constante desde a primeira infância. Assim, o lado cognitivo se desenvolverá em consonância com a qualidade e a quantidade de estímulos oferecidos à criança deficiente visual.

\begin{abstract}
Para que se produza um adequado desenvolvimento do tato no invidente dentro de sua realidade, não será necessário apenas deixar tocar e explorar, deve-se ensinar a tocar, para o que é imprescindível a educação desse sentido. Isso é importante para todas as crianças, porém adquire maior relevância nos casos de invidentes dada a grande função que o tato assume para eles (BALLESTERO-ÁLVAREZ, 2003, p. 52, grifo nosso).
\end{abstract}

Essa estimulação tátil desde tenra idade proporciona uma construção cerebral diferente no que concerne à obtenção e organização das informações de objetos, lugares e sensações. Logo, "a ausência de visão fará com que, para pessoas cegas, o ambiente ao redor consista numa recombinação de elementos sensoriais distinta daquela apreendida pelas pessoas com visão" (MARQUES, 2016, p. 50). A ausência da visão deverá ser substituída pelas memórias criadas a partir das experiências sensoriais das pessoas não visuais.

A preocupação com esse imaginário visual das pessoas não visuais ainda é um mistério para a maioria da população vidente. Em muitos casos, a explicação de algo simples (como uma cor a uma pessoa deficiente visual) se torna um grande quebra-cabeça para o vidente, pois este utiliza recursos próprios de sua percepção de mundo para tentar se fazer entender; porém, tais 
recursos, ditos dessa forma, nem sempre farão sentido ao deficiente visual. Nesse sentido, Fróis9 (2002 apud BUSTOS; FEDRIZZI; GUIMARÃES, 2004) salienta que a quantidade de informações que o indivíduo possui influência a associação que a pessoa cega faz: cor-espaço - se ela apreendeu que vermelho é quente, naturalmente ela vai associar o conceito dessa cor a ambientes e superfícies quentes. Em uma pesquisa qualitativa com pessoas deficientes visuais, as mesmas autoras observaram que a percepção deles com relação a estímulos sensoriais se deu da seguinte maneira:

[...] os cegos percebem uma diferença tonal nas cores, como, por exemplo, um usuário com cegueira congênita se referiu à incidência do sol nas flores como sendo "amarelo claro". [...] e a associação de cores à temperatura, ou seja, a cor amarela como sendo quente e a azul, fria.

Os usuários mencionaram que, das tonalidades salientadas, as cores de que eles mais gostaram foram o amarelo, por associarem a superfícies lisas, ao sol e à luz; o azul, por associarem a superfícies acetinadas, ao céu e à água; o verde, por associarem à natureza; o rosa, pela associação direta com superfícies macias e flores; o branco, por associarem a superfícies macias como tecidos e o algodão, e o laranja, por associarem diretamente à fruta. As cores de que eles não gostaram são o preto e o marrom, por estarem associadas a superfícies pontiagudas, à dor, à escuridão (BUSTOS; FEDRIZZI; GUIMARÃES, 2004, p. 8).

Vamos nos situar agora no âmbito da escola, ao levarmos em conta as classes inclusivas, onde podemos encontrar alunos visuais e não visuais. Nesse espaço, fatores verbais devem ser levados em consideração mais do que de costume, em contraposição com o que ocorre com a gesticulação e a não verbalização dos nomes; deve-se, assim, realizar-se descrições bem detalhadas de tudo o que está acontecendo na aula. Isso evitará a formação de lacunas ao aluno não visual, sobretudo nas aulas de Arte. Ballestero-Álvarez (2003) explica que promover atividades comuns que explorem a multissensorialidade entre todos os discentes pode contribuir com 0

9 FRÓIS, Katja Plotz. Arquitetura Além do Olho ou O Que Temos a Aprender com a Cegueira. Projeto Do Lugar, Colaboração entre Psicologia, Arquitetura e Urbanismo, Del Rio et al (2002), PROARQ, Rio de Janeiro, p.313-316. 
conhecimento e com a descoberta das aptidões uns dos outros. Realça a importância das descrições verbais em situações que envolvam a projeção ou a presença de obras de arte:

Em algumas ocasiões a descrição verbal pode ser a única maneira que o aluno invidente possa perceber algo, como por exemplo, a imagem de uma obra de Arte por ele desconhecida, em uma exposição pública não preparada para esse público, ou numa visita ao planetário, ou na projeção de um filme etc.; o ideal é que posteriormente sejam oferecidos relevos que ilustrem o tema (BALLESTERO-ÁLVAREZ, 2003, p. 45).

O autor acrescenta, ainda, que eventos como a temperatura do local, cheiros, sonoridade do ambiente e até o gosto devem ser explorados pelo aluno não visual, além das descrições verbais e o trabalho de relevo.

\section{IMPLANTAÇÃO E ANÁLISE DO MÉTODO DIDÁTICO-PEDAGÓGICO PARA APRECIAÇÃO DE PINTURAS POR ALUNOS NÃO VISUAIS NAS AULAS DE ARTE DA EDUCAÇÃO BÁSICA}

Neste tópico, abordamos os resultados da pesquisa de Mestrado em Artes do autor, intitulada "Criação de material de apoio para o ensino básico de artes visuais para alunos deficientes visuais". Inicialmente, detalharemos o processo de produção de uma prancha tátil, justificando, ainda, a escolha pela reprodução da obra "Girassóis", de Vincent Van Gogh. Na sequência, apresentamos nossa proposta para o uso efetivo de um método didáticopedagógico que utiliza a prancha em ambiente multissensorial, mostrando nossas hipóteses iniciais antes da aplicação prática da pesquisa. Finalmente, descrevemos como ocorreu a experiência tátil-sinestésica com os sujeitos do estudo. Com isso, serão demonstrados e analisados, qualitativamente, os dados obtidos por meio desses alunos participantes.

O trabalho artístico do escultor José Alfonso Ballestero-Álvarez é pioneiro no Brasil. Seu trabalho de transposição escultórica do conteúdo de 
pinturas é raro no país. Em virtude disso, o artista é constantemente convidado por diversos museus e galerias para reproduzir pinturas em formas táteis.

A prancha utilizada criada especificamente para servir de objeto para a pesquisa foi planejada com o objetivo de realizar uma experiência artística com alguns alunos deficientes visuais da Educação Básica, validando o método didático-pedagógico proposto para que esses alunos não visuais tenham acesso a obras de artes na disciplina de Arte nesse nível de ensino de maneira autônoma, bem como que tenham garantido o seu direito à fruição estética de pinturas artísticas adaptadas as suas condições.

Ballestero-Álvarez, em seu processo de criação, utiliza o procedimento artístico escultórico no início de seu trabalho. Assim, ele primeiro delimita o "tamanho" da prancha a ser produzida, bem como o "volume" que ela ganhará após esse primeiro passo escultórico. O material utilizado na construção da estrutura básica inicial da prancha tátil desta pesquisa foi a massa de modelar oil clay. Com o uso de estecas ${ }^{10}$, artesanalmente, foi reproduzida a imagem da obra "Girassóis", de Vincent Van Gogh.

Figura 1 Processo de confecção da matriz e prancha tátil utilizada nesta pesquisa.

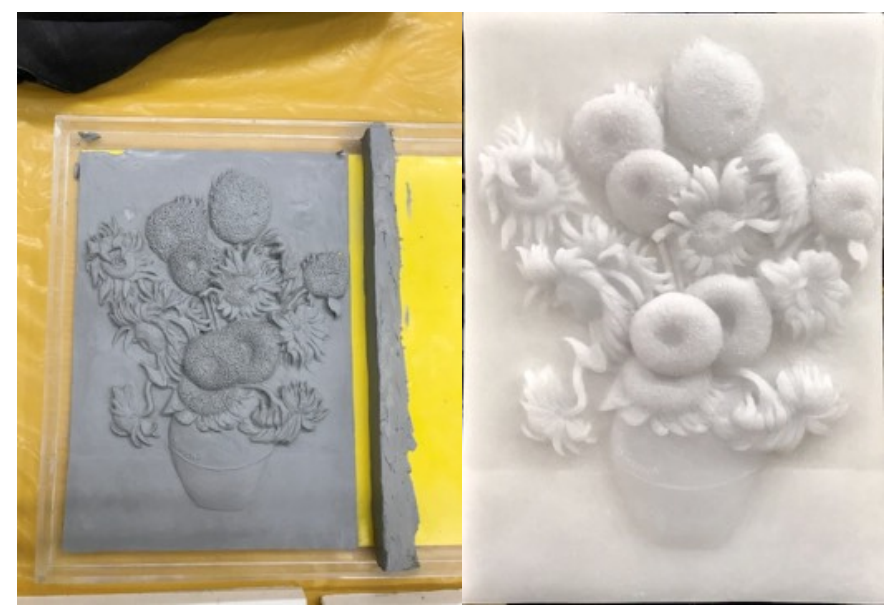

Fonte: acervo do autor.

10 "Estecas" são ferramentas usadas no trabalho de esculpir; são, geralmente, feitas em metal, na forma de; cortadores. São sobretudo ideais para escultura e modelagem em argila. Entre as suas principais funções estão retirar massa, cortar e criar sulcos (CARNEIRO, 2017). 
Após esse trabalho de reprodução, o artista cria um molde preenchendo toda a extensão da obra com silicone. É esse molde que serviu de base para a criação da prancha final. Uma vez criada essa matriz de silicone, esta é preenchida com resina plástica. Depois da secagem, tem-se a prancha tátil de fato, que é finalizada com um acabamento nas laterais. Em seu verso, é fixado um fundo em material E.V.A. para que a prancha não deslize no momento da apreciação.

É importante que expliquemos aqui o porquê de ter sido escolhida, para esta pesquisa, a reprodução da obra "Girassóis", de Van Gogh. Fizemos isso, em primeiro lugar, porque uma de nossas ideias centrais é que, além da apreciação de obras de forma sinestésica, sejam apresentadas aos alunos diferentes concepções acerca das cores. Nesse caso, por exemplo, há a evidente predominância da cor amarela. Além disso, a flor de girassol, retratada na pintura de Van Gogh, existe concretamente no mundo real, o que poderia "facilitar", em um primeiro momento, a sua identificação, sobretudo pelo fato de nossos alunos participantes cursarem os anos iniciais do Ensino Fundamental. Finalmente, o fator determinante para a escolha dessa obra foi o fato de que, mesmo em pesquisas científicas, o uso de obras de arte deve respeitar direitos autorais. Assim, convenientemente, selecionamos uma obra de Domínio Público, ou seja, que não requer nem autorização, nem pagamento para sua veiculação.

Após identificada a ausência de materiais didáticos adaptados ao público alvo dessa investigação, verificamos que através da prancha tátil, o aluno deficiente visual tem perfeitas condições de participar com maior autonomia das aulas de Arte. Queremos dizer com isso que, no momento de exposição e apreciação de conteúdos voltados às artes visuais, sobretudo as pinturas, esses alunos podem (e devem) ser incluídos, a fim de que seus direitos à educação e à arte sejam garantidos.

Contudo, verificamos que não basta apenas indicar materiais que podem ser utilizados nas aulas de Arte com alunos deficientes visuais. Pensando, 
também, no preparo do professor, vimos à necessidade de pensar um método de ensino ${ }^{11}$ para nortear os docentes na utilização do material sugerido, entendemos que a metodologia é a construção de cada professor em sala de aula, então optamos por utilizar a palavra método para demonstrar os caminhos que escolhemos em nossa proposta, ou seja, uma proposição que demonstra como essa prancha tátil pode ser inserida no contexto da Educação Básica.

Nesse sentido, seguindo as orientações de Ballestero-Álvarez (2003), é imprescindível que o professor, para o uso pedagógico das pranchas como instrumento didático, crie um "ambiente de multissensorialidade" com seus alunos cegos; isso resulta em uma aprendizagem artística mais significativa para esse público.

Propomos, então, com esse método didático-pedagógico de ensinoaprendizagem, unir o uso das pranchas táteis à criação de uma atmosfera sinestésica em sala de aula. Tomando como exemplo a prancha tátil desta pesquisa, sugerimos alguns passos a serem levados em consideração ao se trabalhar com esse material na escola de Educação Básica:

- Ao apresentar a obra esculpida na prancha tátil aos alunos, deve-se levar em conta alguns fatores que possam aguçar a experiência sinestésica, os quais servirão como "facilitadores" para a percepção artística do discente não visual. Então, em um primeiro momento, faz-se a contextualização sobre a obra e o tema retratado pelo artista, que podem ser explorados pelo arteeducador de maneira expositiva. No caso da obra "Girassóis", de Vincent Van Gogh, podem ser dadas informações sobre a predominância da cor amarela na pintura.

\footnotetext{
${ }^{11} \mathrm{Na}$ verdade, método, em ciência, não se reduz a uma apresentação dos passos de uma pesquisa. Não é, portanto, apenas a descrição dos procedimentos, dos caminhos traçados pelo pesquisador para a obtenção de determinados resultados. Quando se fala em método, buscase explicitar quais são os motivos pelos quais o pesquisador escolheu determinados caminhos e não outros. São estes motivos que determinam a escolha de certa forma de fazer ciência (CERVO; BERVIAN, 2002).
} 
- Depois, esses alunos podem conhecer, concretamente, a flor girassol, que pode, inclusive, ser levada para a sala de aula. Nesse momento, o professor proporciona ao aluno sentir o cheiro e a textura dessa flor. É possível, ainda, relacionar a flor à produção de mel das abelhas, remetendo-o, nesse sentido, a uma memória gustativa.

- No momento da apreciação da prancha com a obra de Van Gogh ao aluno não visual, além da estimulação tátil, propomos que seja colocada, como música de fundo, a sinfonia "Arabesque", de Debussy, por se tratar de uma melodia que espelha as celebrações de formas na natureza. Com isso, começa-se a colocar em ação dois sentidos - tato e audição. Uma essência com aroma da flor girassol pode ser espirrada no ambiente e, para uma experiência mais completa, uma bala de mel pode ser oferecida à criança, para que, assim, a experiência sensorial seja completa: ao mesmo tempo, quatro sentidos sendo ativados ao mesmo tempo (tato, audição, olfato e paladar). Com isso, provoca-se a atmosfera sinestésica com a estimulação dos sentidos, indo além do tato, para o momento de apreciação estética da prancha.

- Finalmente, após a experiência tátil-sinestésica, um debate entre o discente não visual e os demais alunos pode ser realizado, a fim de que a experiência desse aluno seja compartilhada com os colegas de classe.

Vale ressaltar que o intuito disso é demonstrar que, dentro do ambiente escolar, também é possível que recursos adaptados possam auxiliar o discente e o docente nas aulas de Arte. Por essa razão, realizamos, na prática, essa experiência com alunos deficientes visuais que cursam os anos iniciais do Ensino Fundamental. Assim, foi possível validar, de fato, esse método pelos alunos não visuais, comprovando a nossa hipótese de que é possível uma 
apreciação de obras visuais com esse estímulo multissensorial. Ressaltamos que esse é apenas um dos muitos processos que podem ser trabalhados com esse público. Logo, seja por meio de um processo artesanal, como o que ocorre com a construção de pranchas similares à desta pesquisa, seja por meios tecnológicos, como produtos criados com a impressora 3D, outros métodos de ensino podem ser elaborados com a finalidade de incluir o aluno deficiente visual.

A aplicação prática do método que descrevemos acima foi realizada com dois alunos da Educação Básica (Ensino Fundamental - anos iniciais); um deles apresenta o quadro de cegueira congênita (nascido cego) e a outra é diagnosticada com baixa-visão, conseguindo através de recursos ópticos (óculos) e ampliações de tipos realizar suas atividades sem a utilização de instrução em Braille.

Uma pessoa é considerada cega se corresponde a um dos critérios seguintes: a visão corrigida do melhor dos seus olhos é de 20/200 ou menos, isto é, se ela pode ver a 20 pés (6 metros) o que uma pessoa de visão normal pode ver a 200 pés (60 metros), ou se o diâmetro mais largo do seu campo visual subentende um arco não maior de $20^{\circ}$, ainda que sua acuidade visual nesse estreito campo possa ser superior a 20/200 (CONDE, 2017, p.1).

Nesse contexto, caracteriza-se como tendo visão subnormal ou baixavisão aquele que possui acuidade visual de 6/60 e 18/60 (escala métrica) e/ou um campo visual entre $20^{\circ}$ e $50^{\circ}$. Pedagogicamente, define-se como cego aquele que, mesmo possuindo visão subnormal, necessita de instrução em Braille e como possuidor de baixa-visão aquele que lê tipos impressos ampliados ou com o auxílio de potentes recursos ópticos. Já a cegueira total ou simplesmente amaurose, pressupõe completa perda de visão. A visão é nula, isto é, nem a percepção luminosa está presente. No jargão oftalmológico, usase a expressão "visão zero" (CONDE, 2017).

Neste texto, esses alunos colaboradores serão chamados de sujeitos da pesquisa e apresentados por codinomes, a fim de que sejam respeitadas as 
suas identidades. Uma vez que são menores de idade, os responsáveis foram consultados, com antecedência, pelo pesquisador e assinaram o Termo de Consentimento Livre e Esclarecido, sendo informados sobre o teor da pesquisa e sobre o intuito da investigação dessa experiência artística, no sentido de repensar as maneiras de ensino-aprendizagem de alunos não visuais da Educação Básica.

Para que fosse realizada na prática essa experiência artística com os alunos, dividimos o processo em três etapas, a saber: $1^{a}$ etapa: inicialmente, o pesquisador e o discente têm uma conversa inicial sobre alguns tópicos norteadores (cada aluno experienciou o processo individualmente). Com isso, é realizada uma triagem sobre as percepções do discente acerca das aulas de Arte que frequenta, bem como sobre seu conhecimento com relação a cores, pinturas e materiais artísticos.

$2^{a}$ etapa: na sequência, o pesquisador apresenta ao aluno "O livro negro das cores ${ }^{12}$ de Cottin e Faria (2006)". A história do livro é contada aos sujeitos da pesquisa, sendo coletadas suas percepções acerca das sinestesias nele narradas, a fim de aguçar a ideia sobre a possibilidade de se criar relações sensoriais por meio de estímulos não visuais.

$3^{a}$ etapa: por fim, é criada uma atmosfera sinestésica com som, cheiro e paladar para apresentar a prancha tátil, conforme relatamos no método acima. Assim, toda a percepção desses sujeitos acerca dessa apreciação tátilsinestésica foi coletada.

O roteiro de investigação trabalhado com esses alunos visou avaliar a percepção dos sujeitos da pesquisa em algumas situações. Dessa forma, as cinco primeiras questões buscavam a sua compreensão sobre suas aulas de Arte: 1. Na sua escola, há aulas de Arte? O que você acha dessas aulas? 2. O

12 É uma obra literária de 2006 das autoras Venezuelanas Menena Cottin e Rosana Faría, que narra a percepção do personagem Tomás (deficiente visual) com relação aos cheiros, gostos e formas das cores. Em páginas negras, utilizam-se os códigos braile e verbal simultaneamente, com um método de impressão em verniz localizado, o que permite que as ilustrações fujam do colorido tradicional e possam ser sentidas pelo tato. Isso faz com que seus leitores (deficientes visuais ou não) tenham uma experiência sinestésica com relação às cores, instigando-os a pensar no cheiro, no som e no sabor que a cor pode representar (COTTIN; FARIA, 2006). 
que você faz quando seu professor de Artes chega à classe? 3. Seu professou já falou sobre pinturas e cores alguma vez? 4. Conte para mim como você consegue fazer desenhos ou pinturas. 5. Quais materiais você usa para fazer Arte?

A pergunta seguinte, de número 6 , busca o entendimento desse aluno sobre artistas ou obras que, porventura, possam ter mantido contato: 6 . O que você sabe sobre pinturas e artistas? Você já tocou ou alguém já falou pra você sobre algum quadro?

As últimas perguntas investigam a percepção que esse aluno tem sobre as cores e pretendem trazer à tona a relação da cor com seus sentimentos: 7 . Você conhece as cores? Fale para mim um pouquinho sobre elas. 8. Qual é a sua cor favorita? Explica para mim como é essa cor. 9. Você sente ou se lembra de alguma coisa quando pensa nessa cor? 10. E se eu te disser que as cores têm gostos, cheiros e sons, o que você acha?

Essa experiência tátil-sinestésica aconteceu em uma sala de aula, estando presentes o pesquisador e os sujeitos da pesquisa (com atendimento individual). Todo o processo foi captado com gravador de som.

O sujeito de pesquisa "A" (ou Aluna A) é uma menina de 6 anos de idade, com baixa-visão, que frequenta $\circ 1^{\circ}$ ano do Ensino Fundamental; $O$ sujeito de pesquisa "B" (ou Aluno B), por sua vez, é um menino, com cegueira congênita, de 7 anos, que cursa $\circ 2^{\circ}$ ano do Ensino Fundamental. Esses alunos foram escolhidos por se encaixarem dentro do nível de ensino em que atuamos durante a realização da pesquisa. Além disso, uma vez que escolhemos a obra de Van Gogh, cujo elemento focal são os girassóis, elemento concreto que existe no mundo real (em contraposição a criações mais abstratas), escolhemos esse público pelo fato de os alunos estarem em uma fase de ensino e aprendizagem mais voltada à percepção do mundo que está à sua volta e, também, à identificação de elementos mais concretos.

Os dois alunos têm aulas de Arte com professor específico, além das pedagogas que trabalham com as outras disciplinas curriculares e que 
permanecem o tempo todo em suas respectivas classes, mesmo nas aulas de Arte. Ambos são atendidos, também, na Sala de Recursos da escola que estudam com uma professora que realiza um trabalho mais voltado às necessidades especiais deles e à alfabetização.

Inicialmente, direcionamos nossos questionamentos, às experiências que esses alunos tinham com as aulas de Arte na Escola de Educação Básica. Suas percepções sobre essas aulas apresentaram algumas divergências, as quais creditamos ao fato de a Aluna A ter baixa-visão e de o Aluno B apresentar cegueira total. Nesse sentido, a primeira demonstrou pleno conhecimento de que a aula de Arte tem conteúdos específicos e mostrou interesse pelos assuntos da disciplina:

Aluna A: [A aula de Arte] É muito diferente da aula da minha professora [pedagoga] porque tem um livro diferente. O livro que eu estudo com a minha professora é azul, e o de artes é colorido.

Ela relatou, ainda, como acontecem suas aulas: "Ela [a professora] pede para abrir o livro e ela diz as coisas que têm no livro, que são os desenhos que não precisam mais ser desenhados". A Aluna A sinalizou, ainda, com relação às imagens da lousa ou desenhos, que apresenta dificuldades para compreender as figuras:

\footnotetext{
Aluna A: É porque aquele quadro que está na minha sala não serve para as pessoas de baixa-visão. [...] É só a professora escrever de pincel preto para eu ver melhor; se escrever de azul, fica meio invisível.
}

O Aluno B, por sua vez, apresentou dificuldades para identificar a aula de Arte dentro de sua rotina escolar. Depois de alguns estímulos feitos pelo pesquisador, ele se lembrou de que, em uma aula dessa disciplina, construiu um boneco (que chamou de Max Steel) e fez algumas associações com a cor desse personagem. Quando questionado sobre como acontecem essas aulas, o aluno, que é mais reservado, apresentou a seguinte fala: "Assim, pinta". É interessante nesse caso perceber que, mesmo não tendo acesso visual às 
imagens, o aluno relaciona as aulas de Arte, sobretudo, ao ato de pintar e colorir. Afirmou, ainda, que utiliza "papel mesmo e tem um livro normal". Foi questionado, então, sobre como ele usa o papel e esses outros materiais na aula de Arte, o aluno então se lembrou de uma situação ocorrida em sala de aula. Eis sua resposta:

Aluno B: Acontece assim: desenha um max steel e os superheróis, e a professora me fala o que tem no livro [...] Lápis de cor, não. Eu desenho o Max Steel e os super-heróis e, pra pintar, eu pintei as pedrinhas com a tinta guache.

Com a informação cedida pelo aluno sobre a pintura em pedras, o pesquisador pergunta como ele realizou tal atividade e de que forma escolheu as cores para essa pintura: "Aluno B: Precisa de pincel. A professora que me deu. Aí, a pedrinha eu fiz amarela e foi azul".

O aluno disse que a escolha da cor azul se deu em virtude de uma associação afetiva: "Tava lá, o azul ele é um boneco". Quando questionado novamente sobre a escolha da cor amarela, afirma: "Eu descobri amarela, azul e amarela”. Depois de ser questionado sobre o auxílio de sua professora, acrescenta: "Sim, a professora sempre me ajuda a escolher a cor".

Podemos perceber, então, que a Aluna A tem uma melhor compreensão sobre o que é a aula de Arte, além de ser mais independente, precisando menos da intervenção pedagógica e apresentando a consciência de que, devido à baixa-visão, o método expositivo pode atrapalhar seu entendimento de tudo o que é proposto, especialmente quando está longe do seu alcance visual. Já o aluno B faz associações entre a aula de Arte com materiais artísticos e precisa de intervenções mais constantes de sua professora. Nesse caso, a aula de Arte permanece na explicação oral do que está apresentado no livro e nas adaptações realizadas por sua professora no fazer artístico.

No segundo momento da entrevista, voltamos nossos questionamentos à percepção que os sujeitos de pesquisa têm com relação às cores. Nesse aspecto, a Aluna A afirma conhecer todas as cores e traz referências associativas quando perguntada sobre sua cor favorita: "Aluna A: Vermelho, 
que é uma cor bonita e é dá de pintar coisas vermelhas, como coração, maçã, morango".

Ao ser questionada sobre o que ela sente quando pensa na cor vermelha, responde: "Eu sinto pensando no meu coração; ele bate todo dia". Quando é informada sobre a possibilidade de pensar as cores de maneira sinestésica, obtivemos as seguintes respostas:

Pesquisador: $\mathrm{E}$ se eu te disser que as cores têm gostos, cheiros e sons, o que você acha?

Aluna A: Legal, é tipo um morango e a maçã.

Pesquisador: $E$ você imaginou alguma vez que ela (a cor) podia ter algum barulho ou som?

Aluna A: É, tipo um brinquedo. Um animalzinho de brinquedo que parece um tambor vermelho que tem as baquetas que um homem e uma mulher toca.

Pesquisador: E o cheiro da cor vermelha?

Aluna A: O cheiro do morango e da maçã. Tem o mesmo gosto de quando a gente come.

O Aluno B ressalta que sua cor favorita é o azul e permanece realizando a associação com o personagem de desenho animado: "[Minhas cores] Favoritas são a azul e a amarela, porque é um desenho".

O aluno ainda nos corrige quando perguntamos se ele "assistia sempre a esse desenho"; ele disse que, na verdade, sempre o "escutava".

Quando questionado sobre outras cores, ele faz uma associação com sua bicicleta: "Aluno B: Eu conheço o branco, mas a minha bicicleta é branca e teve uma vez que eu comprei outra bicicleta [...] e eu saio daqui e eu ando no cavalo".

Ele faz essa referência ao cavalo pelo fato de fazer equoterapia. Motivados por isso, questionamos também a cor do animal: "É, pintado de duas cores"; porém, não quis dizer quais eram essas cores, tampouco trouxe maiores referências sobre a cor branca.

O pesquisador ainda o estimulou no sentido de verificar se conseguia realizar associações das cores com coisas de seu cotidiano. Quando questionado sobre o sol, o céu e, mesmo, sobre o cavalo, por exemplo, o aluno 
respondeu: "Aluno B: Sei, é quente. Já me falaram que [o sol] é amarelo. Meu pai me contou. [...] Azul eu pintei, azul do céu. [...] O cavalo passa, a grama é o verde".

Com relação às sinestesias, ele faz uma associação do cheiro da grama com a cor verde - "A grama tem cheiro" -, e nos afirmou que acredita que as cores podem, sim, ter gostos, cheiros e sons.

Destacamos, no Aluno B, a sua reação negativa ao ser apresentado ao "Livro Negro das Cores", de Cottin e Faria (2006) especificamente com relação ao momento em que é tratada a cor preta. Mesmo que no livro ela seja destacada positivamente, como uma cor "macia dos cabelos da mamãe", o aluno prontamente respondeu:

Pesquisador: Essa página está mostrando a cor preta? Você gosta de preto?

Aluno B: Eu gosto não, porque o preto é muito ruim, tudo faz... Pesquisador: Como assim tudo faz?

Aluno B: O preto eu não gosto.

Pesquisador: Por quê?

Aluno B: Porque não.

É provável que essa relação que o Aluno B tem com a cor preta seja correspondente ao afirmado por Bustos, Fedrizzi e Guimarães (2004). As autoras, como apresentamos anteriormente, citam a cor preta entre aquelas que os participantes cegos de suas pesquisas não gostavam, juntamente com a cor marrom, uma vez que são associadas por eles a superfícies pontiagudas, à dor e à escuridão. Assim, pode ser que seja essa a percepção que o sujeito de pesquisa $B$ tenha com relação a essa cor, associando-a a esses sentimentos; contudo, ele não quis dar maiores detalhes sobre isso.

Uma vez realizados os dois momentos anteriores, partimos, finalmente, para a experiência com os dois discentes, fazendo uso da prancha tátil. Assim, em momentos diferentes, contextualizamos os alunos sobre o quadro "Girassóis", de Van Gogh e, na sequência, fizemos algumas perguntas para averiguar o conhecimento de cada um sobre a cor amarela e a flor de girassol. 
O Aluno B afirma já ter ouvido falar da flor do girassol e, quando perguntado sobre a sua cor, diz: “Já lembrei, é amarelo" e a Aluna A afirma: “Eu já vi muitas flores amarelas, eu já também vi o girassol”.

Além desse questionamento, trouxemos à tona uma associação gustativa sobre o que estava sendo comentado e, ao mencionar a produção de mel das abelhas vinda do pólen dessas flores, oferecemos uma balinha de mel a esses alunos, tendo, ainda, como pano de fundo, a melodia da música "Arabesque", de Debussy. O Aluno B mostrou uma reação maior quando a música foi inserida. "Aluno B: Eu acho isso legal. Eu gosto de música de girassol".

Após esse procedimento, entregamos a prancha aos alunos e propusemos a apreciação tátil. Mal tocou a prancha, o Aluno $B$, que tem cegueira total, exclamou: "Olha, é girassol!". A Aluna A disse: "Ele tem uma flor que é o girassol [...] Estou sentindo a bolinha do girassol. Ai, acho que tem um aqui também".

Enquanto tocavam a prancha, a essência de girassol foi espirrada no ambiente e coletamos as seguintes percepções:

Aluno B: Olha, que bom. [...] Sim, tem cheiro de flor.

Aluna A: Acho que tem mais de um [girassol] e estou sentindo um cheiro, parece cheiro de pessoa que já tomou banho. É cheiroso.

No momento da apreciação, averiguamos, ainda, a percepção dos discentes sobre o lugar em que tais girassóis estão na representação tátil. $\mathrm{Na}$ percepção de ambos, houve a associação ao vaso: "Aluna A: Vaso ou pote. É um vaso mesmo", "Aluno B: Estão em um vaso".

A conclusão a que os sujeitos chegaram após a experiência, no caso da Aluna $A$, foi uma associação sinestésica ao final do momento de apreciação tátil: "Acho que eu tô pensando que as flores são cheirosas. Acho que a cor amarela é cheirosa". 
Quando o Aluno B foi questionado sobre a possibilidade de ter outras pinturas que pudessem ser tocadas na escola, afirmou que seria melhor: "Sim, porque ela [a professora] conta tudo e eu não pego na mão; só fica na lousa e eu gosto de sentir as coisas na mão".

Assim, foi encerrada a experiência tátil-sinestésica de apreciação de uma obra de arte adaptada no contexto escolar.

\section{CONCLUSÃO}

Após essa checagem do método, atestamos as hipóteses levantadas nesta pesquisa sobre a condução de uma aula de Arte que não conta com recursos adaptados aos alunos deficientes visuais. Mesmo em discentes tão pequenos, o uso desse material didático, aliado ao método proposto, leva os alunos a se perceberem como sujeitos participantes do contexto escolar.

A prancha é, portanto, muito eficaz, especialmente quando apresentada em ambiente sinestésico. Isso porque as associações a gostos, cheiros e sons familiares desses alunos facilitam a apresentação do que é novo (a pintura adaptada), levando-se em consideração as condições desses alunos. Assim, as referências exteriores de gostos e cheiros que esses alunos trazem em suas memórias podem ser facilmente alcançadas para auxiliar a ideia de cores e, também, a ideia artística de trazer para uma pintura algo concreto e facilmente encontrado pela criança em seu cotidiano.

A apreciação, podemos atestar, aconteceu como se fosse à descoberta de um mistério; esses alunos foram apresentados a algo novo e se dispuseram a explorá-lo de maneira curiosa e interessada. Isso não é tão diferente do que acontece quando pessoas videntes se veem diante de uma obra de arte. Com a visão, exploramos todos os aspectos de uma obra de Arte. Nesse caso, contudo, por intermédio da multissensorialidade, esses sujeitos exploraram e conseguiram acessar memórias sensitivas; chegaram até mesmo a conclusões brilhantes, como o fato de "a cor amarela ser cheirosa", além de se orgulharem 
por poderem ter à mão obras que eles pudessem, de maneira autônoma, explorar sem intervenções.

Assim, é importante que resgatemos, neste momento, a ideia de que a garantia da inclusão nas escolas de ensino regular foi uma grande conquista para as crianças que apresentam algum tipo de deficiência. Todavia, de nada adianta incluir essas crianças em um sistema de ensino sem que haja uma preparação, adequação profissional e material que as acolha de forma adequada. Foi nesse sentido que nos lançamos ao desafio de realizar esta pesquisa, a fim de que fossem sugeridas ações concretas que pudessem ser utilizadas no espaço escolar com o objetivo de mostrar aos alunos que apresentam algum tipo de deficiência (em nosso caso, os alunos deficientes visuais) que eles também são sujeitos que fazem parte do contexto escolar, sem prioridades ou ficar à margem: todos são, nas suas diferenças, sujeitos iguais.

Buscamos, com o estudo da sinestesia, relacionar a ideia de que a Arte está ligada essencialmente aos sentidos humanos, pois, mesmo com a ausência da visão, outros estímulos podem ser desencadeados, o que remonta a ideia de uma multissensorialidade nas artes visuais para as pessoas cegas. É importante que deixemos claro que jamais tivemos a intenção de induzir que pessoas cegas tivessem noções visuais sobre cores ou sobre obras de artes. $O$ que tentamos propor foi que esses sujeitos, mesmo não contando com o sentido da visão, tivessem total direito ao acesso e à fruição estética da Arte em seu sentido lato. Se a Arte é universal e está intrínseca aos seres humanos, as pessoas deficientes visuais não podem ser colocadas à margem dessa maravilha e é nosso dever, como professores e pesquisadores da área de Artes Visuais, pensar em maneiras de mediar e de permitir o acesso desses sujeitos.

Então, nesse contexto, combinamos o uso de pranchas táteis com outros sentidos, de modo sinestésico, para pensar um método didático e pedagógico que pudesse ser aplicado em alunos não visuais da Educação Básica. O método demonstrou eficácia quando aplicado aos sujeitos de 
pesquisa. Verificamos, por exemplo, que as aulas de Arte dos alunos colaboradores deste estudo acontecem, sobretudo, de maneira expositiva, com algumas intervenções pedagógicas e com os mesmos materiais usados pelos outros alunos da turma (videntes). A ausência de material adaptado foi verificada na investigação. Com relação à apreciação de imagens, no caso do Aluno $B$, cego congênito, sua professora acaba descrevendo as imagens que são fornecidas pelo livro e desenhadas na lousa. O próprio aluno relata que gostaria de sentir, em suas mãos, o que está sendo ensinado pela professora. Nesse caso, inferimos que a ausência da adaptação vai promover uma aprendizagem impessoal. Assim, consideramos que a proposta desse método tátil-sinestésico para as aulas de Arte dos alunos não visuais poderia suprir essa lacuna.

Demonstramos, portanto, que existe a possibilidade de se levar essa iniciativa inclusiva para a escola de Educação Básica e que, por meio dela, podemos pensar uma aula de Artes Visuais que vai exercer a sua função também com os discentes não visuais, promovendo momentos de fruição e emoção autônomas, para que eles possam ser "tocados" pela Arte por meio do olhar de seus sentimentos.

\section{REFERÊNCIAS}

ARAGUAIA, Mariana. Síndrome de Charles Bonnet. 2017. Disponível em <http:// brasilescola.uol.com.br/doencas/sindrome-charles-bonnet.htm>. Acesso em 19 mar. de 2017.

BALLESTERO-ÁLVAREZ, Jose Alfonso. Multissensorialidade no ensino de desenho a cegos. Dissertação (Mestrado em Artes Plásticas) - Escola de Comunicações e Artes, Universidade de São Paulo/USP, São Paulo, 2003.

BRASIL. Lei $\mathbf{n}$. 9.394, de 20 de dezembro de 1996. Estabelece as diretrizes e bases da educação nacional. Disponível em: <http://www.planalto.gov.br/ccivil_03/leis/ L9394.htm>. Acesso em: 8 abr. 2016.

Lei $\mathrm{n}^{\circ}$ 13.146, de 6 de julho de 2015. Institui a lei brasileira de inclusão da pessoa com deficiência (estatuto da pessoa com deficiência). Brasília, 2015. Disponível em: http://www.planalto.gov.br/ccivil_03/_ato2015-2018/2015/lei/ I13146.htm. Acesso em: 26 set. 2017. 
BUSTOS, Carolina; FEDRIZZI, Beatriz; GUIMARÃES, Lia Buarque de Macedo. PERCEPÇÃO DOS DEFICIENTES VISUAIS CORES X TEXTURAS. In: I Conferência Latino-Americana de construção sustentável; $X$ Encontro Nacional de Tecnologia do Ambiente Construído. 2004, São Paulo. Anais. São Paulo: ANTAC, 2004.

CARNEIRO, Ivane Angélica. Artes Visuais: Práticas tridimensionais. Curitiba: Intersaberes, 2017.

CERVO, A. L. BERVIAN, P. A. Metodologia científica. 5.ed. São Paulo: Prentice Hall, 2002.

CHKLOVSKI, Viktor. A Arte como Procedimento. In TOLEDO, Dionísio de Oliveira (Org). Teoria da Literatura, Formalistas Russos. Porto Alegre: Editora Globo, 1978.

CONDE, Antônio João Menescal. Definição de cegueira e baixa visão. 2017. Disponível em: <http://www.ibc.gov.br/images/conteudo/AREAS_ESPECIAIS/ CEGUEIRA_E_BAIXA_VISAO/ARTIGOS/Def-de-cegueira-e-baixa-viso.pdf>. Acesso em: 20 mar. 2017.

CONHECIMENTO GERAL. Ouvido absoluto. 2016. Disponível em: <https:// www.conhecimentogeral.inf.br/ouvido_absoluto/>. Acesso em: 19 mar. 2017.

COTTIN, Menena; FARIA, Rosana. O livro negro das cores. Rio de Janeiro: Pallas, 2006.

DEBUSSY, CLAUDE. Arabesque. In: Electronic Philharmonic Music Library. Patrick Smith: Electronic Philharmonic, 2009, 1 CD.

HOUAISS, Antonio; VILLAR, Mauro de Salles. Dicionário eletrônico Houaiss da língua portuguesa. Rio de Janeiro: Objetiva, 2009. Versão 1.0 CD-ROM.

KANDINSKY, Wassily. Do espiritual na arte. 3. ed. Brasil: Martins, 2000.

MARQUES, Sarah Barreto. Sinestesia das pessoas cegas: novas possibilidades de informação. Dissertação (Mestrado em Ciência da Informação). Programa de Pósgraduação em Ciência da Informação, Universidade Federal do Rio de Janeiro /UFRJ. Rio de Janeiro, 2016.

PRESA, Carla Patrícia Magalhães. Sinestesia na arte. Dissertação (Mestrado em Design Multimédia). Programa de Pós-graduação em Design Multimédia da Universidade da Beira Interior/UBI. Covilhã, 2008. 